\title{
Plasma BDNF concentrations and the antidepressant effects of six ketamine infusions in unipolar and bipolar depression
}

\author{
Wei Zheng ${ }^{\text {Corresp., } 1}{ }^{1}$, Yan-Ling Zhou ${ }^{1}$, Cheng-Yu Wang ${ }^{1}$, Xiao-Feng Lan ${ }^{1}$, Bin Zhang ${ }^{1}$, Su-Miao Zhou ${ }^{1}$, Su Yan ${ }^{1}$, Yu- \\ Ping Ning \\ ${ }^{1}$ Psychiatry, The Affiliated Brain Hospital of Guangzhou Medical University (Guangzhou Huiai Hospital), Guangzhou, China \\ 2 Psychiatry, The first School of Clinical Medicine, Southern Medical University, Guangzhou, China \\ Corresponding Authors: Wei Zheng, Yu-Ping Ning \\ Email address: zhengwei0702@163.com, ningjeny@126.com
}

Objectives: Accumulating evidence has implicated that brain derived neurotrophic factor (BDNF) is thought to be involved in the pathophysiology ofdepression, but its correlation with ketamine's antidepressant efficacy focusing on Chinese individuals with depression is not known. This study was aim to determine the correlation of plasma BDNF (pBDNF) concentrations and ketamine's antidepressant efficacy. Methods: Ninety-four individuals with depression received six intravenous infusions ketamine $(0.5 \mathrm{mg} / \mathrm{kg})$. Remission and response were defined as Montgomery-Asberg Depression Rating Scale (MADRS) scores less than 10 and a reduction of $50 \%$ or more in MADRS scores, respectively. Plasma was collected at baseline and at $24 \mathrm{~h}$ and 2 weeks after completing six ketamine infusions (baseline, $13 \mathrm{~d}$ and $26 \mathrm{~d}$ ). Results: A significant improvement in MADRS scores and pBDNF concentrations was found after completing six ketamine infusions compared to baseline (all $p s<0.05$ ). Higher baseline pBDNF concentrations were found in ketamine responders/remitters $(11.0 \pm 6.2 / 10.1 \pm 5.8 \mathrm{ng} / \mathrm{ml})$ than nonresponders/nonremitters $(8.0 \pm 5.5 / 9.2 \pm 6.4 \mathrm{ng} / \mathrm{ml}$ ) (all ps<0.05). Baseline pBDNF concentrations were correlated with MADRS scores at $13 \mathrm{~d}(\mathrm{t}=-2.011, \mathrm{p}=0.047)$ or $26 \mathrm{~d}(\mathrm{t}=-2.398, \mathrm{p}=0.019)$ in depressed patients (all $p s<0.05$ ). Subgroup analyses found similar results in individuals suffering from treatment refractory depression. Conclusion: This preliminary study suggests that baseline pBDNF concentrations appeared to be correlated with ketamine's antidepressant efficacy in Chinese patients with depression. debar", 2 
Abstract: 211 words

Text: 2,043 words

Tables: 3

Figures: 2

Supplemental Tables: 2

Supplemental Figures: 2

\title{
Plasma BDNF concentrations and the antidepressant effects of six
} ketamine infusions in unipolar and bipolar depression

Running title: BDNF and ketamine

\author{
1Wei Zheng, MD, PhD; \\ ${ }^{1}$ Yan-Ling Zhou, MD, PhD; \\ ${ }^{1}$ Cheng-Yu Wang, MD, PhD; \\ ${ }^{1}$ Xiao-Feng Lan, MD; \\ ${ }^{1}$ Bin Zhang, MD, PhD; \\ 1Su-Miao Zhou, MD; \\ 1Su Yan, MD; \\ ${ }_{1,2 *}$ Yu-Ping Ning, MD, PhD
}

1. The Affiliated Brain Hospital of Guangzhou Medical University (Guangzhou Huiai Hospital), Guangzhou, China;

2. The first School of Clinical Medicine, Southern Medical University, Guangzhou, Guangdong, China

*Address correspondence to Dr. Yu-Ping Ning, the Affiliated Brain Hospital of Guangzhou Medical University (Guangzhou Huiai Hospital), Guangzhou, China; Email address: ningjeny@126.com. 


\section{Disclosure/Conflicts of Interest}

32 The authors declare no conflicts of interest in conducting this study or

33 preparing the manuscript.

\section{Financial support}

36 This work was supported by the National Natural Science Foundation of

37 China (81801343, 81801345), Guangdong Basic and Applied Basic Research

38 Foundation (2019A1515011366), the National Key Research and

39 Development Program of China (2016YFC0906300), Science and Technology

40 Department of Guangdong Province major science and technology

41 (2016B010108003) and Guangzhou Municipal Psychiatric Disease Clinical

42 Transformation Laboratory (201805010009). The funding source had no role

43 in the study design, analysis or interpretation of data or in the preparation of

44 the report or decision to publish.

\section{Acknowledgements}

None. 
Abstract

51 Objectives: Accumulating evidence has implicated that brain derived

52 neurotrophic factor (BDNF) is thought to be involved in the pathophysiology

53 of depression, but its correlation with ketamine's antidepressant efficacy

54 focusing on Chinese individuals with depression is not known. This study was

55 aim to determine the correlation of plasma BDNF ( $p B D N F$ ) concentrations

56 and ketamine's antidepressant efficacy.

Methods: Ninety-four individuals with depression received six intravenous

58 infusions ketamine $(0.5 \mathrm{mg} / \mathrm{kg})$. Remission and response were defined as

59 Montgomery-Asberg Depression Rating Scale (MADRS) scores less than 10

60 and a reduction of $50 \%$ or more in MADRS scores, respectively. Plasma was

61 collected at baseline and at $24 \mathrm{~h}$ and 2 weeks after completing six ketamine

62 infusions (baseline, $13 \mathrm{~d}$ and $26 \mathrm{~d}$ ).

63 Results: A significant improvement in MADRS scores and pBDNF 64 concentrations was found after completing six ketamine infusions compared

65 to baseline (all $p s<0.05$ ). Higher baseline pBDNF concentrations were found 66 in ketamine responders/remitters $(11.0 \pm 6.2 / 10.1 \pm 5.8 \mathrm{ng} / \mathrm{ml})$ than 67 nonresponders/nonremitters $(8.0 \pm 5.5 / 9.2 \pm 6.4 \quad \mathrm{ng} / \mathrm{ml}) \quad($ all $p s<0.05)$. Baseline pBDNF concentrations were correlated with MADRS scores at $13 \mathrm{~d}$

$69(t=-2.011, p=0.047)$ or $26 d(t=-2.398, p=0.019)$ in depressed patients

70 (all $p s<0.05$ ). Subgroup analyses found similar results in individuals 
71 suffering from treatment refractory depression.

72 Conclusion: This preliminary study suggests that baseline pBDNF

73 concentrations appeared to be correlated with ketamine's antidepressant

74 efficacy in Chinese patients with depression.

75 Key words: Brain-derived neurotrophic factor; ketamine; depression;

76 response 
Introduction

79 Accumulating evidence suggests that glutamatergic abnormalities are

80 associated with the pathophysiology of mood disorders (Yüksel \& Öngür

81 2010). Numerous early studies had consistently reported that an antagonist

82 of glutamatergic $\mathrm{N}$-methyl-D-aspartate (NMDA) receptors ketamine at

83 subanesthetic doses could result in fast-acting and sustained antidepressant

84 effects in individuals suffering from unipolar and bipolar depression ( $N a$ \&

85 Kim 2021; Phillips et al. 2020). For example, ketamine's repeated

86 administration had quick and enduring antidepressant and antisuicidal

87 effects in depressed patients (Kryst et al. 2020).

88 The precise mechanisms underlying subanesthetic intravenous

89 ketamine's antidepressant actions are still incompletely understood (Rong et

al. 2018). A recent animal study found that blockade of NMDA receptors

increased the induction of a-amino-3-hydroxy-5-methyl-4-

92 isoxazole propionic acid (AMPA) receptor expression in models of depression,

93 and subsequent activation of the mammalian target of rapamycin (mTOR)

94 pathway was needed for the rapid and robust antidepressant action of

95 ketamine (Li et al. 2010). Growing evidence implicated neurotrophic factors,

96 such as brain-derived neurotrophic factor (BDNF), played an important in

97 the pathophysiology of mood disorders (Duman 2004; Duman \& Monteggia

98 2006). BDNF is a key protein in facilitating and supporting memory growth 
99 and neuronal survival (Leal et al. 2017). Rapid and transient upregulation of

100 BDNF reversed or blocked atrophy and cell loss in patients with depression, 101 and it may be a critical component in subanesthetic intravenous ketamine's 102 antidepressant actions (Haile et al. 2014).

103 In general, BDNF plays a role in the pathophysiology of schizophrenia 104 (Singh et al. 2020) and mood disorders (Molendijk et al. 2014; Sagud et al. 105 2016). For example, several studies found that individuals suffering from 106 depression had lower serum BDNF concentrations and pBDNF concentrations

107 than that of healthy subjects (Molendijk et al. 2014; Sagud et al. 2016) and 108 recovered after successful antidepressant therapy (Brunoni et al. 2008; Polyakova et al. 2015). Central and peripheral BDNF is positively correlated with the response and remission of antidepressant treatment (Lee \& Kim

111 2010). Notably, Kurita et al. reported that remitted than nonremitted

112 depressed patients appeared to have higher pBDNF concentrations, and 113 these concentrations were associated with the Montgomery-Asberg 114 Depression Rating Scale (MADRS) scores (Kurita et al. 2012).

115 BDNF as a predictor of ketamine's antidepressant efficacy in individuals 116 suffering from treatment-refractory depression (TRD) has been investigated,

117 but with inconsistent findings. For example, several open-label studies on 118 ketamine and BDNF found a negative association of the increase in BDNF 119 following a single ketamine infusion with the severity of depression (Cornwell 
120 et al. 2012; Duncan et al. 2013). Another study found that BDNF did not

121 mediate single subanesthetic intravenous ketamine's antidepressant efficacy

122 (Machado-Vieira et al. 2009). However, no studies had been published to

123 examine the relationship of pBDNF concentrations and serial subanesthetic

124 intravenous ketamine infusions' antidepressant efficacy in Chinese

125 individuals suffering from depression.

126 The present study was performed to examine the correlation of pBDNF

127 concentrations and six subanesthetic intravenous ketamine's antidepressant

128 efficacy $(0.5 \mathrm{mg} / \mathrm{kg})$ administered thrice weekly over two weeks in Chinese

129 individuals suffering from unipolar and bipolar depression. In this study, we

130 hypothesized that serial intravenous subanesthetic ketamine would increase

131 pBDNF concentrations, and baseline pBDNF concentrations would be

132 associated with ketamine's antidepressant efficacy in individuals suffering

133 from depression.

\section{Methods}

136

Study sample

137 Data of the current study were collected from an open-label clinical study, 138 which examined serial intravenous subanesthetic ketamine's antidepressant 139 and antisuicidal efficacy in individuals suffering from depression and was performed between November 2016 to December 2017 (registration number: 
141 ChicCTR-OOC-17012239) (Zheng et al. 2018). The Ethics Committee of the

142 Affiliated Brain Hospital of Guangzhou Medical University approved the 143 current trial's protocol (Ethical Application Ref: 2016-030) and written 144 informed consent was obtained from all participants.

145 All subjects were recruited based on the following inclusion criteria: (1) 146 aged between 18 and 65 years, without psychotic symptoms; (2) diagnosis 147 of unipolar or bipolar depression by a certified psychiatrist according to the 148 Structured Clinical Interview for DSM-V (SCID-5) criteria, with a score of 17 149 or more for the Hamilton Depression Rating Scale (HAMD-17) (Hamilton 150 1960); (3) suffering from TRD, which was defined as nonresponse to 2 or 151 more antidepressant treatments, or experiencing suicidal ideation as 152 measured with the Scale for Suicidal Ideations (Beck et al. 1979); (4) had 153 no a history of neurological diseases (e.g., dementia), drug or alcohol abuse;

154 (5) negative urine toxicology; (6) were not pregnant or breast feeding; and 155 (7) had no any unstable medical illness (e.g., cerebrovascular diseases).

Treatment

All patients received a thrice-weekly ketamine treatment regimen for 2 159 weeks, with a follow-up period of two weeks. The method for repeated 160 ketamine infusions was described in detail in our early trial (Zheng et al. 161 2018). Briefly, vital signs and clinical status of participants were 
162 routinely monitored, and each subject received six intravenous infusions of

$1630.5 \mathrm{mg} / \mathrm{kg}$ ketamine over $40 \mathrm{~min}$. During the study period, all subjects 164 continued taking psychotropic agents.

\section{Response and remission}

167 The MADRS (Montgomery \& Asberg 1979; Zhong et al. 2011) was used to assess depressive symptoms at baseline, $1 \mathrm{~d}$ after the sixth infusion (13 d),

169 and 2 weeks after the last ketamine treatments (26 d). Remission and 170 response were defined as MADRS scores less than 10 (Zimmerman et al. 1712004 ) and a reduction of $50 \%$ or more in MADRS scores, respectively.

\section{Measurement of pBDNF concentrations}

174 Plasma was collected at baseline, $13 \mathrm{~d}$ and $26 \mathrm{~d}$, which were stored at -80 ${ }^{\circ} \mathrm{C}$ until further use. In accordance with the manufacturer's instructions, in this study a commercially available enzyme-linked immunosorbent assay

177 (ELISA) kit (EMD Millipore Corporation, MA, USA) was used to measure pBDNF concentrations.

\section{Statistical analysis}

181 The Mann-Whitney $U$ test was conducted to analyze nonnormally distributed 182 continuous data, and independent $t$ tests were applied for normally 
183 distributed continuous data. For categorical variables, the Fisher's exact test

184 or Chi-squared test were applied for comparisons between groups 185 (responders versus nonresponders and remitters versus nonremitters). 186 Changes in pBDNF concentrations and MADRS scores over time and 187 subgroup differences (responders/nonresponders and remitters/nonremitters) 188 were examined using linear mixed models. Bivariate correlation analysis was 189 applied in order to determine the correlation of baseline pBDNF 190 concentrations and MADRS scores at $13 \mathrm{~d}$ and $26 \mathrm{~d}$ in individuals suffering 191 from unipolar or bipolar depression. Multiple linear regression were also used 192 to examine the independent association of baseline pBDNF concentrations 193 and MADRS scores at $13 \mathrm{~d}$ and $26 \mathrm{~d}$. MADRS scores were entered as the 194 dependent variable, while Baseline pBDNF concentrations were entered as 195 independent variables and other variables including age, gender, body 196 weight, body mass index, psychiatric family history, previous hospitalization, 197 psychiatric comorbidity, and age of onset were entered as covariate 198 variables. Furthermore, an additional analysis was also performed on a subsample of patients with TRD in this study. IBM SPSS version 23 software 200 (IBM Corporation, Armonk, NY, USA) was used in this study, and significance was set as $p$-value less than 0.05 . 
204 Ninety-four individuals (aged 18 to 62 years) with unipolar or bipolar 205 depression who provided a baseline blood sample were enrolled. Of these 206 patients, $81.9 \%$ (77/94) fulfilled the diagnostic criteria of TRD. Baseline 207 pBDNF concentrations with a mean value of $10.1 \mathrm{ng} / \mathrm{ml}$, ranged from 0.9 to $20827.2 \mathrm{ng} / \mathrm{ml}$.

209

210

Treatment outcome and BDNF

211 After the last ketamine treatments, the rates of response and remission

212 were $65.3 \%(64 / 94)$ and $51.1 \%(48 / 94)$, respectively. The rates of response

213 and remission for patients with TRD were $68.8 \%(53 / 77)$ and $51.9 \%(40 / 77)$,

214 respectively, after completion of six ketamine infusions. Higher baseline 215 pBDNF concentrations were found in ketamine responders/remitters $216(11.0 \pm 6.2 / 10.1 \pm 5.8 \quad \mathrm{ng} / \mathrm{ml})$ than nonresponders/nonremitters $217(8.0 \pm 5.5 / 9.2 \pm 6.4 \mathrm{ng} / \mathrm{ml})$ (all $p s<0.05$, Table 1$)$.

218 Linear mixed models showed that MADRS scores and pBDNF 219 concentrations exhibited significant time main effects between responders 220 and nonresponders and remitters and nonremitters (Table 2). Ketamine 221 produced a significant change in MADRS scores and pBDNF concentrations at $22213 \mathrm{~d}$ and $26 \mathrm{~d}$ when compared to baseline (Figure 1 and Figure 2). Similar 223 results were found in patients with TRD (Supplemental Table 1, 224 Supplemental Figure 1 and 2). 


\section{Correlation of BDNF and MADRS scores}

227 Correlation analyses showed significant associations between pBDNF 228 concentrations at baseline and MADRS scores at $13 \mathrm{~d}$ and $26 \mathrm{~d}$ in depressed 229 patients (all ps<0.05; Table 3). The significant association of pBDNF 230 concentrations at baseline and MADRS scores at $13 \mathrm{~d}(\mathrm{t}=-2.011, \mathrm{p}=0.047)$ 231 and $26 \mathrm{~d}(\mathrm{t}=-2.398, \mathrm{p}=0.019)$ remained in multiple regression analysis.

232 Similar results were found in patients with TRD (Supplemental Table 2).

Discussion

235 This is the first study to determine pBDNF concentrations after six 236 subanesthetic intravenous ketamine in Chinese individuals suffering from 237 unipolar and bipolar depression and to investigate the correlation of pBDNF 238 concentrations at baseline and six subanesthetic intravenous ketamine's 239 antidepressant efficacy. The following main findings included: 1) ketamine 240 increased pBDNF at $13 \mathrm{~d}$ and $26 \mathrm{~d}$ compared to baseline; 2) 241 responders/remitters had significantly higher baseline pBDNF concentrations 242 than nonresponders/nonremitters; 3) MADRS scores showed significant 243 improvement at both time points across the total sample in 244 responders/remitters and nonresponders/nonremitters compared to baseline; 4) baseline pBDNF concentrations were related with MADRS scores; and 5) 
246 additional analysis of patients with TRD also found that pBDNF

247 concentrations were related with the antidepressant outcome of ketamine in 248 patients with TRD.

249 Consistent with an animal study after single ketamine infusion (Pytka et 250 al. 2018), our study demonstrated that ketamine increased pBDNF 251 concentrations after six ketamine infusions. Although 252 nonresponders/nonremitters had significantly lower pBDNF concentrations at 253 baseline than responders/remitters, repeated ketamine infusions failed to 254 significantly increase pBDNF concentrations in responders/remitters when 255 compared to nonresponders/nonremitters. Similarly, a previous study found 256 no changes in pBDNF concentrations in individuals suffering from TRD after 257 completion of an intravenous infusion of ketamine compared to baseline 258 (Machado-Vieira et al. 2009). However, Haile et al. found that pBDNF 259 concentrations were significantly increased following a single ketamine 260 infusion in responders compared to nonresponders (Haile et al. 2014). 261 Therefore, these findings should be confirmed by randomized controlled 262 trials.

263 The observed rapid reduction in MADRS scores lasted up to 2 weeks, 264 replicating the previous findings (Rasmussen et al. 2013; Shiroma et al. 265 2014). However, the primary objective of this study is to examine the 266 association of baseline pBDNF concentrations and six subanesthetic 
267 intravenous ketamine's antidepressant efficacy. Several studies examined 268 the association of pBDNF concentrations with the antidepressant response of 269 a single infusion of ketamine, but these findings are inconsistent (Haile et al. 270 2014; Lee \& Kim 2010). For instance, one study reported that pBDNF 271 concentrations were related with the severity of depression (Haile et al. 272 2014). However, Machado-Vieira et al.'s study reported a negative finding on 273 the association of pBDNF concentrations and ketamine's antidepressant 274 efficacy (Machado-Vieira et al. 2009).

275 Notably, several animal studies reported that increased hippocampal and 276 cortical BDNF expression can partly accounting for ketamine's 277 antidepressant-like efficacy (Autry et al. 2011; Réus et al. 2011). pBDNF 278 concentrations were lower in individuals suffering from depression compared 279 to healthy controls (Kishi et al. 2017; Munno et al. 2013) and increased after 280 receiving antidepressants (Munno et al. 2013; Polyakova et al. 2015), 281 electroconvulsive therapy (Luan et al. 2020; Piccinni et al. 2009), and 282 repeated transcranial magnetic stimulation (Yukimasa et al. 2006). 283 Therefore, neurotrophic factors, such as BDNF, might be involved in 284 ketamine's antidepressant mechanism. Notably, BDNF is implicated in the 285 regulation of synaptic plasticity, including the synaptic recruitment of AMPA 286 receptors. Growing studies indicate that synaptic plasticity is altered in 287 individuals with depression (Machado-Vieira et al. 2006; Schloesser et al. 
288 2008; Zarate et al. 2006), and ketamine's antidepressant efficacy may be 289 attributed to the synaptic potentiation of neural circuits mediated by 290 increased AMPA-to-NMDA glutamate receptors (Maeng \& Zarate 2007).

291 The following limitations should be acknowledged. First, the participants 292 continued receiving previous medications and lacked a washout period 293 during the study, which may have affected pBDNF concentrations. However, 294 the combination of ketamine and other antidepressants for individuals with 295 depression is increasingly being used in the real-world clinical setting 296 (Shiroma et al. 2014). Second, the sample size was small in the current 297 study. Third, the possible impact of subjective evaluation was inevitable due 298 to lack of a control group. Fourth, some comprehensive analyses, such as 299 the mediating and moderating effect analysis, were not conducted in this 300 study. Finally, brain BDNF concentrations and other key neurobiological 301 mediators, such as mTOR, were not directly measured. However, BDNF 302 crosses the blood-brain barrier, and pBDNF concentrations are closely 303 correlated with cortical BDNF concentrations, and likely reflect brain BDNF 304 concentrations (Pillai et al. 2010; Poduslo \& Curran 1996).

305 In conclusion, this preliminary study suggests that baseline pBDNF 306 concentrations appeared to be correlated with ketamine's antidepressant 307 efficacy in Chinese patients with depression. 


\section{References}

Autry AE, Adachi M, Nosyreva E, Na ES, Los MF, Cheng PF, Kavalali ET, and Monteggia LM. 2011. NMDA receptor blockade at rest triggers rapid behavioural antidepressant responses. Nature 475:91-95.

Beck AT, Kovacs M, and Weissman A. 1979. Assessment of suicidal intention: the Scale for Suicide Ideation. $J$ Consult Clin Psychol 47:343-352.

Brunoni AR, Lopes M, and Fregni F. 2008. A systematic review and meta-analysis of clinical studies on major depression and BDNF levels: implications for the role of neuroplasticity in depression. Int $J$ Neuropsychopharmacol 11:1169-1180.

Cornwell BR, Salvadore G, Furey M, Marquardt CA, Brutsche NE, Grillon C, and Zarate CA, Jr. 2012. Synaptic potentiation is critical for rapid antidepressant response to ketamine in treatment-resistant major depression. Biol Psychiatry 72:555-561.

Duman RS. 2004. Role of neurotrophic factors in the etiology and treatment of mood disorders. Neuromolecular Med 5:11-25.

Duman RS, and Monteggia LM. 2006. A neurotrophic model for stress-related mood disorders. Biol Psychiatry 59:1116-1127.

Duncan WC, Sarasso S, Ferrarelli F, Selter J, Riedner BA, Hejazi NS, Yuan P, Brutsche N, Manji HK, Tononi G, Zarate CA. 2013. Concomitant BDNF and sleep slow wave changes indicate ketamine-induced plasticity in major depressive disorder. Int J Neuropsychopharmacol 16:301-311.

Haile CN, Murrough JW, Iosifescu DV, Chang LC, Al Jurdi RK, Foulkes A, Iqbal S, Mahoney JJ, 3rd, De La Garza R, 2nd, Charney DS, Newton TF, Mathew SJ. 2014. Plasma brain derived neurotrophic factor (BDNF) and response to ketamine in treatment-resistant depression. Int J Neuropsychopharmacol 17:331-336.

Hamilton M. 1960. A rating scale for depression. J Neurol Neurosurg Psychiatry 23:56-62.

Kishi T, Yoshimura R, Ikuta T, and Iwata N. 2017. Brain-derived neurotrophic factor and major depressive disorder: evidence from meta-analyses. Front Psychiatry 8:308.

Kryst J, Kawalec P, Mitoraj AM, Pilc A, Lasoń W, and Brzostek T. 2020. Efficacy of single and repeated administration of ketamine in unipolar and bipolar depression: a meta-analysis of randomized clinical trials. Pharmacol Rep 72:543-562.

Kurita M, Nishino S, Kato M, Numata Y, and Sato T. 2012. Plasma brain-derived neurotrophic factor levels predict the clinical outcome of depression treatment in a naturalistic study. PLoS ONE 7:e39212.

Leal G, Bramham CR, and Duarte CB. 2017. BDNF and hippocampal synaptic plasticity. Vitam Horm 104:153-195.

Lee BH, and Kim YK. 2010. The roles of BDNF in the pathophysiology of major depression and in antidepressant treatment. Psychiatry Investig 7:231-235.

Li N, Lee B, Liu RJ, Banasr M, Dwyer JM, Iwata M, Li XY, Aghajanian G, and Duman RS. 2010. mTORdependent synapse formation underlies the rapid antidepressant effects of NMDA antagonists. Science 329:959-964.

Luan S, Zhou B, Wu Q, Wan $\mathrm{H}$, and $\mathrm{Li} \mathrm{H}$. 2020. Brain-derived neurotrophic factor blood levels after electroconvulsive therapy in patients with major depressive disorder: A systematic review and metaanalysis. Asian J Psychiatr 51:101983.

Machado-Vieira R, Yuan P, Brutsche N, DiazGranados N, Luckenbaugh D, Manji HK, and Zarate CA, Jr. 2009. Brain-derived neurotrophic factor and initial antidepressant response to an N-methyl-D-aspartate antagonist. 
J Clin Psychiatry 70:1662-1666.

Machado-Vieira R, Zarate CA, Jr., and Manji HK. 2006. Emerging novel treatments for severe mood disorders involving cellular plasticity cascades. Curr Psychos Ther Rep 4:181-190.

Maeng S, and Zarate CA, Jr. 2007. The role of glutamate in mood disorders: results from the ketamine in major depression study and the presumed cellular mechanism underlying its antidepressant effects. Curr Psychiatry Rep 9:467-474.

Molendijk ML, Spinhoven P, Polak M, Bus BA, Penninx BW, and Elzinga BM. 2014. Serum BDNF concentrations as peripheral manifestations of depression: evidence from a systematic review and meta-analyses on 179 associations (N=9484). Mol Psychiatry 19:791-800.

Montgomery SA, and Asberg M. 1979. A new depression scale designed to be sensitive to change. Br J Psychiatry 134:382-389.

Munno D, Sterpone S, Fania S, Cappellin F, Mengozzi G, Saroldi M, Bechon E, and Zullo G. 2013. Plasma brain derived neurotrophic factor levels and neuropsychological aspects of depressed patients treated with paroxetine. Panminerva Med 55:377-384.

Na KS, and Kim YK. 2021. Increased use of ketamine for the treatment of depression: Benefits and concerns. Prog Neuropsychopharmacol Biol Psychiatry 104:110060.

Phillips JL, Norris S, Talbot J, Hatchard T, Ortiz A, Birmingham M, Owoeye O, Batten LA, and Blier P. 2020. Single and repeated ketamine infusions for reduction of suicidal ideation in treatment-resistant depression. Neuropsychopharmacology 45:606-612.

Piccinni A, Del Debbio A, Medda P, Bianchi C, Roncaglia I, Veltri A, Zanello S, Massimetti E, Origlia N, Domenici L et al. Marazziti D, Dell'Osso L. 2009. Plasma Brain-Derived Neurotrophic Factor in treatmentresistant depressed patients receiving electroconvulsive therapy. Eur Neuropsychopharmacol 19:349-355.

Pillai A, Kale A, Joshi S, Naphade N, Raju MS, Nasrallah H, and Mahadik SP. 2010. Decreased BDNF levels in CSF of drug-naive first-episode psychotic subjects: correlation with plasma BDNF and psychopathology. Int J Neuropsychopharmacol 13:535-539.

Poduslo JF, and Curran GL. 1996. Permeability at the blood-brain and blood-nerve barriers of the neurotrophic factors: NGF, CNTF, NT-3, BDNF. Brain Res Mol Brain Res 36:280-286.

Polyakova M, Stuke K, Schuemberg K, Mueller K, Schoenknecht P, and Schroeter ML. 2015. BDNF as a biomarker for successful treatment of mood disorders: a systematic \& quantitative meta-analysis. $J$ Affect Disord 174:432-440.

Pytka K, Głuch-Lutwin M, Kotańska M, Waszkielewicz A, Kij A, and Walczak M. 2018. Single administration of HBK-15-a Triple 5-HT(1A), 5-HT(7), and 5-HT(3) receptor antagonist-reverses depressive-like behaviors in mouse model of depression induced by corticosterone. Mol Neurobiol 55:3931-3945.

Réus GZ, Stringari RB, Ribeiro KF, Ferraro AK, Vitto MF, Cesconetto P, Souza CT, and Quevedo J. 2011. Ketamine plus imipramine treatment induces antidepressant-like behavior and increases CREB and BDNF protein levels and PKA and PKC phosphorylation in rat brain. Behav Brain Res 221:166-171.

Rasmussen KG, Lineberry TW, Galardy CW, Kung S, Lapid MI, Palmer BA, Ritter MJ, Schak KM, Sola CL, Hanson AJ, Frye MA. 2013. Serial infusions of low-dose ketamine for major depression. $J$ Psychopharmacol 27:444-450.

Rong C, Park C, Rosenblat JD, Subramaniapillai M, Zuckerman H, Fus D, Lee YL, Pan Z, Brietzke E, Mansur RB, Cha DS, Lui LMW, McIntyre RS. 2018. Predictors of response to ketamine in treatment resistant major 
depressive disorder and bipolar disorder. Int J Environ Res Public Health 15.

Sagud M, Nikolac Perkovic M, Vuksan-Cusa B, Maravic A, Svob Strac D, Mihaljevic Peles A, Zivkovic M, Kusevic Z, and Pivac N. 2016. A prospective, longitudinal study of platelet serotonin and plasma brainderived neurotrophic factor concentrations in major depression: effects of vortioxetine treatment. Psychopharmacology (Berl) 233:3259-3267.

Schloesser RJ, Huang J, Klein PS, and Manji HK. 2008. Cellular plasticity cascades in the pathophysiology and treatment of bipolar disorder. Neuropsychopharmacology 33:110-133.

Shiroma PR, Johns B, Kuskowski M, Wels J, Thuras P, Albott CS, and Lim KO. 2014. Augmentation of response and remission to serial intravenous subanesthetic ketamine in treatment resistant depression. $J$ Affect Disord 155:123-129.

Singh J, Verma R, Raghav R, Sarkar S, Sood M, and Jain R. 2020. Brain-derived neurotrophic factor (BDNF) levels in first-episode schizophrenia and healthy controls: A comparative study. Asian J Psychiatr 54:102370.

Yüksel C, and Öngür D. 2010. Magnetic resonance spectroscopy studies of glutamate-related abnormalities in mood disorders. Biol Psychiatry 68:785-794.

Yukimasa T, Yoshimura R, Tamagawa A, Uozumi T, Shinkai K, Ueda N, Tsuji S, and Nakamura J. 2006. Highfrequency repetitive transcranial magnetic stimulation improves refractory depression by influencing catecholamine and brain-derived neurotrophic factors. Pharmacopsychiatry 39:52-59.

Zarate CA, Jr., Singh J, and Manji HK. 2006. Cellular plasticity cascades: targets for the development of novel therapeutics for bipolar disorder. Biol Psychiatry 59:1006-1020.

Zheng W, Zhou YL, Liu WJ, Wang CY, Zhan YN, Li HQ, Chen LJ, Li MD, and Ning YP. 2018. Rapid and longerterm antidepressant effects of repeated-dose intravenous ketamine for patients with unipolar and bipolar depression. J Psychiatr Res 106:61-68.

Zhong BL, Wang Y, Chen HH, and Wang XH. 2011. Reliability, validity and sensitivity of Montgomery-Åsberg Depression Rating Scale for patients with current major depressive disorder [in Chinese]. Chinese Journal of Behavioural Medicine and Brain Sciences 20:85-87.

Zimmerman M, Posternak MA, and Chelminski I. 2004. Derivation of a definition of remission on the MontgomeryAsberg depression rating scale corresponding to the definition of remission on the Hamilton rating scale for depression. J Psychiatr Res 38:577-582.

(1)




\section{Table $\mathbf{1}$ (on next page)}

Comparison of baseline sample characteristics between responders and nonresponders and between remitters and nonremitters 
Table 1. Comparison of baseline sample characteristics between responders and nonresponders and between remitters and nonremitters.

2

\begin{tabular}{|c|c|c|c|c|c|c|c|c|c|}
\hline \multirow{3}{*}{ Variables } & \multirow{3}{*}{$\begin{array}{l}\begin{array}{c}\text { Total } \\
(\mathrm{n}=94)\end{array} \\
\mathrm{N}(\%)\end{array}$} & \multicolumn{4}{|c|}{ Response after six ketamine infusions } & \multicolumn{4}{|c|}{ Remission after six ketamine infusions } \\
\hline & & \multirow{2}{*}{$\begin{array}{c}\begin{array}{c}\text { Responders } \\
(n=64)\end{array} \\
N(\%)\end{array}$} & \multirow{2}{*}{$\begin{array}{c}\begin{array}{c}\text { Nonresponders } \\
(n=30)\end{array} \\
N(\%)\end{array}$} & \multicolumn{2}{|c|}{ Statistics } & \multirow{2}{*}{$\begin{array}{c}\text { Remitters } \\
(n=48)\end{array}$} & \multirow{2}{*}{$\begin{array}{c}\text { Nonremitters } \\
(n=46)\end{array}$} & \multicolumn{2}{|c|}{ Statistics } \\
\hline & & & & $\mathrm{X}^{2}$ & $p$ & & & $X^{2}$ & $p$ \\
\hline Female & $50(53.2)$ & $35(54.7)$ & $15(50.0)$ & 0.2 & 0.67 & $22(45.8)$ & $28(60.9)$ & 2.1 & 0.14 \\
\hline Employment & $38(40.4)$ & $29(45.3)$ & $9(30.0)$ & 2.0 & 0.16 & $22(45.8)$ & $16(34.8)$ & 1.2 & 0.28 \\
\hline \multirow[t]{2}{*}{ Married } & $50(53.2)$ & $35(54.7)$ & $15(50.0)$ & 0.2 & 0.67 & $27(56.3)$ & $23(50.0)$ & 0.4 & 0.54 \\
\hline & Mean (SD) & Mean (SD) & Mean (SD) & $\mathrm{T} / \mathrm{Z}$ & $p$ & Mean (SD) & Mean (SD) & $\mathrm{T} / \mathrm{Z}$ & $p$ \\
\hline Age (years) & $34.6(11.6)$ & $35.1(11.2)$ & $33.4(12.5)$ & -0.7 & 0.50 & $34.8(10.9)$ & $34.3(12.4)$ & -0.2 & 0.83 \\
\hline Education (years) & $12.4(3.3)$ & $12.8(3.2)$ & $11.4(3.4)$ & -2.0 & 0.049 & $12.6(3.2)$ & $12.1(3.4)$ & -0.6 & 0.53 \\
\hline BMI $\left(\mathrm{kg} / \mathrm{m}^{2}\right)$ & $22.4(3.6)$ & $22.5(3.5)$ & $22.2(3.8)$ & -0.4 & 0.66 & $22.7(3.9)$ & $22.1(3.2)$ & 0.8 & 0.43 \\
\hline $\begin{array}{l}\text { Duration of illness } \\
\text { (months) }\end{array}$ & $102.5(98.3)$ & $106.3(101.7)$ & $94.5(91.9)$ & $--{ }^{a}$ & 0.51 & $107.3(101.4)$ & $97.6(95.9)$ & $--^{-a}$ & 0.58 \\
\hline $\begin{array}{l}\text { Baseline MADRS } \\
\text { scores }\end{array}$ & $31.9(7.6)$ & $31.8(7.6)$ & $32.2(7.6)$ & 0.3 & 0.80 & $30.6(7.3)$ & $33.3(7.7)$ & -1.8 & 0.08 \\
\hline $\begin{array}{l}\text { Baseline plasma } \\
\text { BDNF levels (ng/ml) }\end{array}$ & $10.1(6.2)$ & $11.0(6.2)$ & $8.0(5.5)$ & $--^{a}$ & 0.01 & $10.1(5.8)$ & $9.2(6.4)$ & $--_{--}{ }^{a}$ & 0.045 \\
\hline \multicolumn{10}{|c|}{$\begin{array}{l}\text { aMann-Whitney U test. } \\
\text { Bolded values are } p<0.05 \text {. }\end{array}$} \\
\hline
\end{tabular}




\section{Table 2 (on next page)}

Comparison of MADRS scores and plasma BDNF levels between respondersandnonrespondersand between remitters andnonremitters in patients with unipolar and bipolar depression using linear mixed model analysis 
1 Table 2. Comparison of MADRS scores and plasma BDNF levels between 2 responders and nonresponders and between remitters and nonremitters in patients with 3 unipolar and bipolar depression using linear mixed model analysis.

4

\begin{tabular}{|l|l|c|c|c|c|c|c|}
\hline \multirow{2}{*}{ Outcomes } & \multirow{2}{*}{ Variables } & \multicolumn{2}{c|}{$\begin{array}{c}\text { Group-by-time } \\
\text { interaction }\end{array}$} & \multicolumn{2}{c|}{ Time main effect } & \multicolumn{2}{c|}{ Group main effect } \\
\cline { 3 - 9 } & & $\mathrm{F}$ & $p$ & $\mathrm{~F}$ & $p$ & $\mathrm{~F}$ & $p$ \\
\hline $\begin{array}{l}\text { Responders vs. nonr } \\
\text { esponders }\end{array}$ & MADRS scores & 59.79 & $<\mathbf{0 . 0 0 1}$ & 223.39 & $<\mathbf{0 . 0 0 1}$ & 59.32 & $<\mathbf{0 . 0 0 1}$ \\
\cline { 2 - 10 } & $\begin{array}{l}\text { lasma BDNF } \\
\text { levels (ng/ml) }\end{array}$ & 0.04 & 0.837 & 8.55 & $<\mathbf{0 . 0 0 1}$ & 3.90 & $\mathbf{0 . 0 2 4}$ \\
\hline $\begin{array}{l}\text { Remitters } \\
\text { vs. nonremitters }\end{array}$ & MADRS scores & 74.95 & $<\mathbf{0 . 0 0 1}$ & 263.13 & $<\mathbf{0 . 0 0 1}$ & 29.52 & $<\mathbf{0 . 0 0 1}$ \\
\cline { 2 - 10 } & $\begin{array}{l}\text { Plasma BDNF } \\
\text { levels (ng/ml) }\end{array}$ & 0.02 & 0.888 & 6.40 & $\mathbf{0 . 0 0 3}$ & 2.61 & 0.079 \\
\hline
\end{tabular}

Bolded values are $p<0.05$.

Abbreviations: BDNF=brain-derived neurotrophic factor; MADRS=the Montgomery-Asberg Depression Rating Scale. 


\section{Table 3(on next page)}

Correlation of baseline plasma BDNF levels and MADRS scores at $13 \mathrm{~d}$ or $26 \mathrm{~d}$ in patients with unipolar and bipolar depression 
1 Table 3. Correlation of baseline plasma BDNF levels and MADRS scores at $13 \mathrm{~d}$ or $26 \mathrm{~d}$ 2 in patients with unipolar and bipolar depression.

3

\begin{tabular}{|c|c|c|}
\hline Variables & MADRS scores at $13 \mathrm{~d}$ & MADRS scores at $26 \mathrm{~d}$ \\
\hline \multirow{2}{*}{$\begin{array}{l}\text { Baseline plasma BDNF } \\
\text { levels }(\mathrm{ng} / \mathrm{ml})\end{array}$} & $r=-0.220$ & $r=-0.278$ \\
\hline & $p=0$ & $\rho=0$ \\
\hline \multicolumn{3}{|c|}{$\begin{array}{l}\text { Bolded values are } p<0.05 \text {. } \\
\text { Abbreviations: BDNF=brain-derived neurotrophic factor; MADRS=the } \\
\text { Montgomery-Asberg Depression Rating Scale; } r=\text { Pearson coefficient of }\end{array}$} \\
\hline
\end{tabular}

4 
Figure 1

Figure 1. Change in depressive symptoms in patients with unipolar and bipolar depression.

${ }^{\#}$ Significant difference was found when comparing baseline to the indicated times $(p<0.05)$.

"Significant difference was foundbetween respondersandnonrespondersand between remitters andnonremitters at the indicated times $(p<0.05)$. Abbreviations: MADRS $=$ the Montgomery-Asberg Depression Rating Scale. 
A

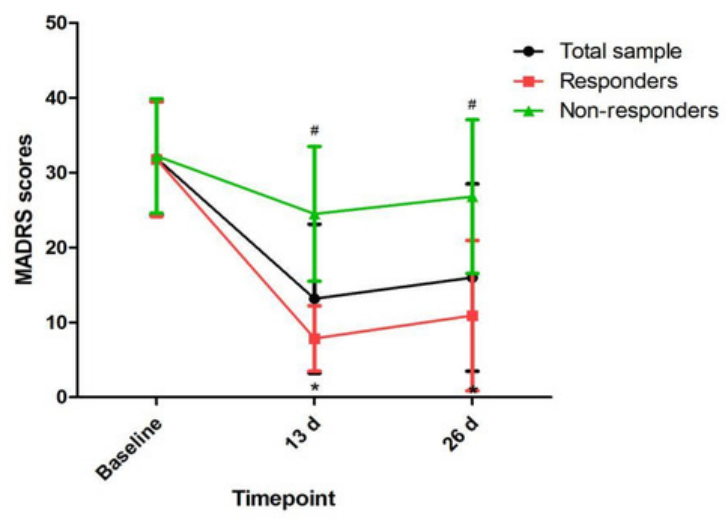

B

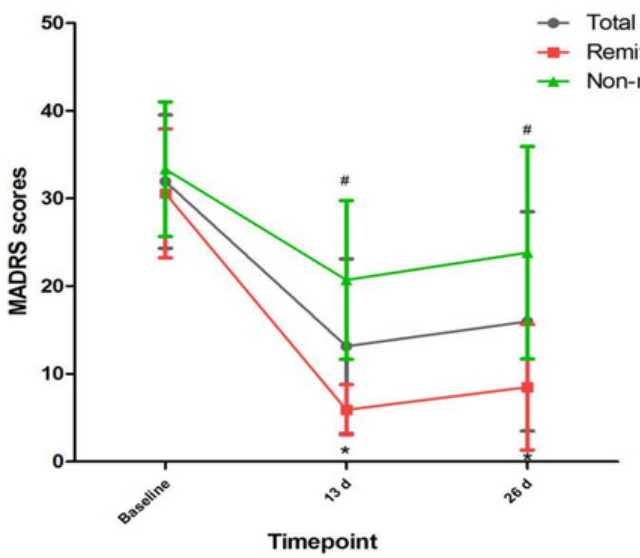


Figure 2

Figure 2. Change in plasma BDNF levels in patients with unipolar and bipolar depression.

${ }^{\#}$ Significant difference was found when comparing baseline to the indicated times $(p<0.05)$.

"Significant difference was found between respondersandnonrespondersand between

remitters andnonremitters at the indicated times $(p<0.05)$. Abbreviations: $B D N F=$ brainderived neurotrophic factor. 


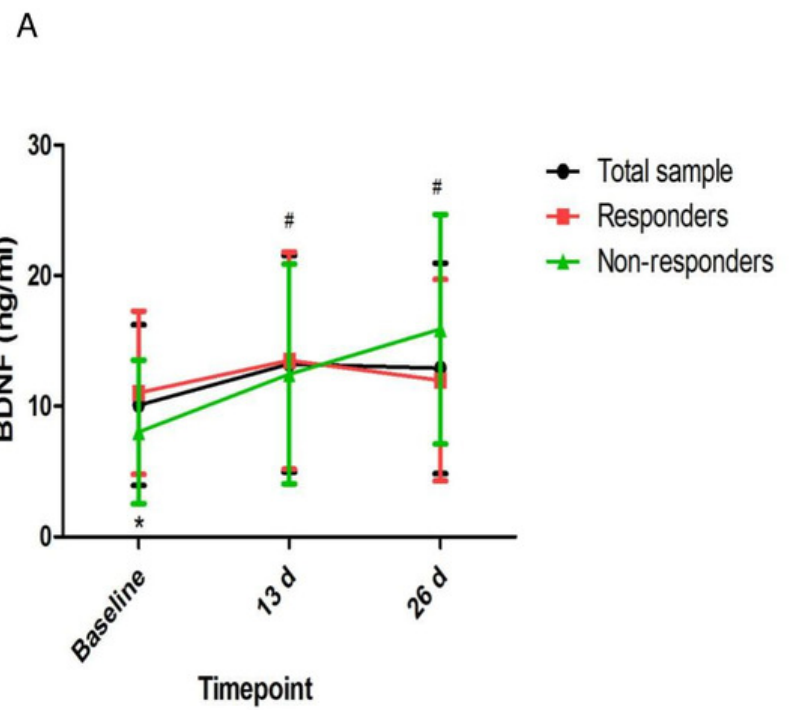

B

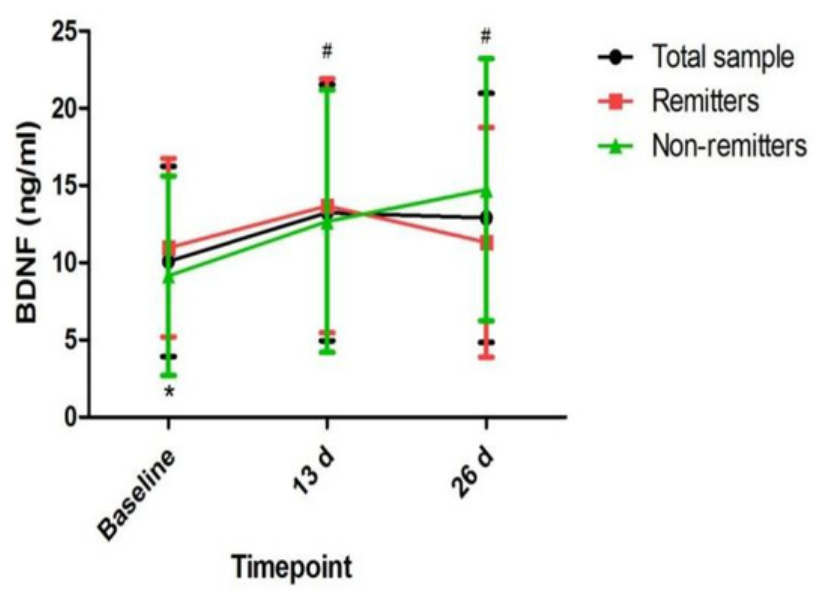

